\title{
Treatment Options for Incisional Hernias.
}

\author{
Kastriot Haxhirexha ${ }^{1,2 *}$, Agron Dogjani ${ }^{2,3}$, Ferizat Dika- Haxhirexha ${ }^{2}$
}

Received: 01 December 2021 / Accepted: 24 December 2021 / Published online: 20 January 2022

This article is published with open access at https://journal.astes.org.al

(C) The author(s) 2022. \& Copyright (C) 2022, the Albanian Society for Trauma and Emergency Surgery

(c) The Albanian Journal of Trauma and Emergency Surgery is an Open Access Journal. All articles are distributed under the terms of the Creative Commons Attribution Non-Commercial License: http://creativecommons.org/licenses/by-nc/4.0/) which permits unrestricted non-commercial use, distribution, and reproduction in any medium provided the original work is properly cited.

\begin{abstract}
Introduction; Despite the many ways and materials available to surgeons today, correction of incisional hernias continues to be a real challenge for surgeons.

Aim of the study: To show our experience in the treatment of patients with incisional hernias.

Material and methods: subject of this study are 69 patients operated during the period May 2015 to May 2020 in the Clinical Hospital of Tetovo.

Results: Correction of the incisional hernia in 24 patients was performed by closing the defect without the use of prosthetic materials (herniorrhaphy). In 38 patients, hernioplasty was performed using polypropylene mesh, while in six of them the correction of the defect was performed through composite dual mesh. The incidence of other complications such as operative wound infection, hematoma, seroma, postoperative pain was lower in persons where the incisional hernia was corrected with composite dual mesh

Conclusion: Correction of incisional hernias with the use of prosthetic materials marks a lower rate not only of recurrence but also of other postoperative complications.
\end{abstract}

Keywords; incisional hernias, complications, prosthetic materials, recurrence

\section{Introduction}

Incisional hernias continue to be a major problem in general surgery. The causes of incision hernias after a surgical intervention are numerous, while the main ones are operative wound infection, obesity, male sex, diabetes, constipation, $\mathrm{BPH}$, etc.

The best way to correct incisional hernias remains the one with prosthetic materials, of which the most widely used are polypropylene mesh. Correction of incisional hernias without the use of prosthetic materials is associated

Original article, no submission or publication in advance or in parallel

* Corresponding author:

Prof. Dr, Kastriot Haxhirexha MD, PhD

$\bowtie$ dr.kastriot@gmail.com

1 Clinical Hospital - Tetovo, Republic of North MACEDONIA

2 Medical Faculty - State University of Tetovo, Republic of North MACEDONIA

3 Department of Surgery, Faculty of Medicine, University of Medicine of Tirana, ALBANIA with a high degree of tension in the suture line, which in turn promotes tissue ischemia, while this causes cutting of the abdominal muscles and recurrence of the defect.

The use of prosthetic mesh for the correction of incisional hernias mainly avoids the occurrence of these complications thus marking a higher success rate and lower incidence of postoperative complications.

\section{Aim of the study}

To show our experience in the treatment of patients with incisional hernias. The epidemiological characteristics of the patients as well as the risk factors for the occurrence of incisional hernias, and incidence of postoperative complications, will be in the focus of this study.

\section{Material and Methods}

The study includes 69 patients operated with incisional hernia in the general surgery ward at the Clinical Hospital of Tetovo during the period March 2015-2020. Data on the type of surgical intervention as well as postoperative complications were extracted from the records of operated patients. 


\section{Results}

From the total number of patients operated in our clinic with the diagnosis of incisional hernia, in the period from January 2015-2020, it results that out of 69 patients 41 of them or $59.4 \%$ are female and 28 or $40.6 \%$ male.

The average age of all operated patients was 48.1 years, with the average age of women being 46.85 years, while that of men 53.28 years.

Regarding smoking, only five out of 41 women which underwent hernioplasty because of incisional hernia or 12.9 $\%$ of them were smokers, while among men the percentage of smokers was much higher, respectively twelve out of 28 operated patients or $42.8 \%$ of them were smokers.

Another factor that has a major impact on increasing the risk of developing incisional hernias is obesity. Even in our study it turns out that the percentage of overweight patients is very high. Thus, in the group of female patients who after the first intervention have had as a complication the development of incisional hernia, from a total of 41 women 31 of them were overweight. The data analysis shows that only ten out of 41 women with incisional hernias were normal weight $(24.4 \%), 16$ other patients $(39 \%)$ were overweight, obese $11(26.8 \%)$ and morbidly obese 4 (9.8 $\%)$.

In the male group the percentage of overweight patients is slightly lower, respectively 9 of them $(32.1 \%)$ were normal weight, while $13(46.4 \%)$ were overweight, five $(17.9 \%)$ were obese and only one $(3.6 \%)$ was morbidly obese.

Surgical interventions which are mostly complicated by the occurrence of incisional hernias have been several.

Thus, in women, the interventions with the highest incidence of incisional hernia were gynaecological interventions, whether for various gynaecological pathologies or as a complication after caesarean delivery.

Out of 41 women treated with incisional hernias in this time period, 18 of them were due to previous gynaecological interventions. In eleven other patients, the cause of the incisional hernia was cholecystectomy. Surgical procedures in the umbilical region were the cause of umbilical incisional hernias in five patients.

Four women with incisional hernias, have had hemicolectomy for the treatment of colorectal cancer, while surgical interventions due to appendectomy and mechanical ileus were the cause of incisional hernia in three patients.

In men, the situation changes because the most common surgical intervention complicated with incisional hernias was inguinal hernioplasty, respectively - 13 patients out of 28 included in the study were operated because of inguinal hernia, in five patients the cause of incisional hernia was surgical intervention in the umbilical region. Incisional hernia after hemicolectomy for the treatment of colorectal cancer is registered in four patients, whereas perforated ulcers in two other patients. Laparoscopic procedure, open cholecystectomy and urological intervention have been the cause of incisional hernias in four other patients.
Of all patients included in the study 14 of them or $23.7 \%$ were smokers. From 28 males who were part of this study, 11 of them were active smokers $(39.3 \%)$, while in the female group of 41 patients only five of them had consumed tobacco $(12.2 \%)$.

In the group of male patients five of them suffered from Benign Prostatic Hyperplasia (BPH) and had significant problems with urination.

Another disorder that has an impact on the incidence of hernias in general is constipation. Out of 69 patients included in this study, 12 of them (17.9\%) referred for this concern, respectively eight women and four men suffered from chronic constipation.

In our practice correction of incisional hernias is done through various surgical techniques. Of the 69 patients included in this study, in 24 of them or $34.8 \%$ the correction of the defect was done through free tissue techniques, without the use of prosthetic materials. In this group of 24 patients, 9 of them were males and 15 females.

In most patients the correction of incisional hernias is done through the use of various prosthetic materials. Thus, in 38 of them (55\%) - (14 males and 18 females), we used polypropylene mesh for correction of the defect, while in six patients $(10.2 \%)$ - four males and two females, the correction was done through the so-called Dual Intraperitoneal mesh.

Of the postoperative complications, the most common was wound infection, recorded in eight patients. In five cases the infection occurred in patients in whom the correction of the hernia was done through free tissue techniques, while in the other three cases the correction of hernias was done using prosthetic materials, respectively Prolene ${ }^{\circledR}$ mesh. In none of the patients with intraperitoneal mesh was registered operative wound infection.

Seroma occurred in seven patients, of whom six were cases corrected with Prolene ${ }^{\circledR}$ mesh, and the other one with intraperitoneal mesh. In patients operated with the classical method, without the use of prosthetic materials, this complication was not recorded.

Wound haemorrhage in the first days after surgery was recorded in five patients, three in the group of those operated without prosthetic materials, while two in those with Prolene ${ }^{\circledR}$ mesh.

All patients operated on in our ward due to incisional hernia, and included in this study, were continuously monitored during the first two years after surgery.

Recurrence of the hernia was observed in three of these patients during the first two years. In all three patients, the correction of the hernia was done through free tissue methods, without the use of prosthetic materials. The type of incisional hernias in these patients were different, respectively in one of them the recurrence was after correction of inguinal hernia, in another after colon resection and gynaecological intervention in another patient.

Recently two of these patients were re-operated, while the correction of the hernia was done through prosthetic materials. 


\section{Discussion}

Incisional hernias still remain a concern for the general surgeon, despite the fact that today there are various prosthetic materials available for use, which make the treatment of these complication more successful.

In terms of frequency, incisional hernias are the second most common hernias, and this is due to many factors. Some of the factors that affect the incidence of incisional hernias are the increased number of abdominal surgical interventions, increased middle age of the patients, increased incidence of overweight, increased incidence of chronic comorbidities, etc. Elderly patients usually have chronic comorbidities, which significantly increase the risk of developing this complication $[1,2]$.

Reported incidence of incisional hernias within the first year after abdominal surgery, varies in different studies, and generally ranges from $3-7 \%$. One of the most influential factors in the appearance of incisional hernias it is estimated to be wound infection in the postoperative period $[4,5,10$, $11]$.

In terms of age, the mean age of the patients included in our study is about 48.1 years, while an approximate mean age of patients with recurrent hernias is also referred by many other authors [3].

In our study, the number of women is significantly higher than that of men, respectively $60.3 \%$ of patients are women, while $39.7 \%$ men.

There are many other studies on incision hernias that refer to a higher incidence of these hernias in women [6, $7,15]$.

The reason for this predominance of female compared to males, is the large number of women who undergo various gynaecological interventions, including births by caesarean section, which resulted in weakening of the abdominal wall muscles. At the same time, being overweight is another factor that puts women at risk for this complication.

In terms of frequency, the second group of patients with recurrent hernias in our study are those operated on for inguinal hernias. In our experience all these patients were male, respectively 13 patients or about $22 \%$.

Umbilical hernias show the same incidence in both sexes. In our study we had ten patients with incisional hernias as a result of complication after these surgical interventions.

Other causes of incisional hernias have been laparoscopic interventions, colorectal resection, appendectomy, etc.

Based on our experience, it turns out that the risk factor for the appearance of incisional hernia may be several, of which the most significant were wound infection, constipation, high BMI values, smoking etc. As for men, $\mathrm{BPH}$ seems to be a risk factor for the appearance of an incisional hernia.

All of these disorders have been described as risk factors by various authors in many studies $[8,9]$.
In our practice we have corrected incisional hernias through different techniques, part of them with free tissue correction, and others with the use of prosthetic materials.

Similar to many other studies [15], our experience shows better results after correction of incisional hernias with prosthetic material.

From prosthetic materials we have mainly used light Prolene ${ }^{\circledR}$ mesh, although recently we have corrected some incisional hernias through dual meshes which are placed inside the abdominal cavity. Such meshes show lower rates of recurrence and postoperative complications [12, 13]. Correction of incisional hernias through dual mesh was performed in six patients included in this study.

The use of prosthetic materials for the correction of incisional hernias is widely used everywhere in the world. Most authors who deal with the correction of these complications, report an increase use of these materials for correction of recurrent hernias. It is now proven that the use of prosthetics materials shows a lower degree of postoperative complications and recurrence $[12,20]$.

An extensive retrospective study undertaken by the Cochrane Collaboration and EU Hernia Trial lists Collaboration, also showed a lower incidence of hernia recurrence in patients in whom the defect correction is done through prosthetic materials [14]

Another earlier study by Jack A. [9] also found a lower incidence of postoperative complications, especially recurrence, after correction of the hernia with prosthetic material.

It is estimated that actually in the US the correction of over $90 \%$ of all forms of abdominal hernias is done with the use of prosthetic materials [12].

However, in our practice the percentage of patients in whom the correction of incisional hernias is done through prosthetic materials is lower, mainly due to economic reasons.

Postoperative complications in our patients were some, of which the most common were wound infection, haemorrhage and seroma formation.

Infection as well as wound haemorrhage were recorded in three patients, thus marking an incidence of about $5 \%$ for each complication.

There are studies that show a lower incidence of surgical wound infections after hernia repair [16, 17], just as there are authors such as Mudge $M$ et al. that show a similar incidence or even higher than that of our study [18].

In this study seroma was registered in four patients, and in all of them correction of incisional hernias was done with the use of prosthetic materials.

All patients of our study were followed for two consecutive years and no recurrence of hernia was recorded in any of them.

In a large study by Ellis et al [3] in which data for about 300 patients operated on with incisional hernia were analysed, up to one year after surgery, no recurrent cases were registered, whereas after two to five years, the 
percentage of patients in whom recurrence of the hernia was recorded went to $5.8 \%$. (Ellis et all.[3])

In another large study of Jankins, recurrence rate of incisional hernias after surgical treatment is around $3.8 \%$ [19].

Conclusion: Correction of incisional hernias with the use of prosthetic materials marks a lower rate not only of recurrence but also of other postoperative complications.

COI Statement: This paper has not been submitted in parallel. It has not been presented fully or partially at a meeting or podium or congress. It has not been published nor submitted for consideration beforehand.

This research received no specific grant from any funding agency in the public, commercial, or non-profit sectors. There are no relevant or minor financial relationships from authors, their relatives or next of kin with external companies.

Disclosure: The authors declared no conflict of interest. No funding was received for this study.

\section{References}

1. Borab ZM, Shakir S, Lanni MA, Tecce MG, MacDonald J, Hope WW et al. Does prophylactic mesh placement in elective, midline laparotomy reduce the incidence of incisional hernia? A systematic review and meta-analysis. Surgery 2017; 161(4): 1149-1163.

2. Schumpelick V, Junge $K$, Klinge U, Conze J. Incisional Hernia - Pathogenesis, Presentation and Treatment. Dtsch Arztebl 2006; 103(39): 2553-2558

3. Ellis H, Gajraj H, George CD. Incisional hernias when do they occur? Br J Surg. 1983; 70: 290.

4. Gilbert AI, Felton LL. Infection in inguinal hernia repair considering biomaterials and antibiotics. Surg Gynecol Obstet. 1993; 177: 126.

5. Itatsu K, Yokoyama Y, Sugawara G, Kubota H, Tojima Y, Kurumiya Y, Kono H, Yamamoto H, Ando M, Nagino M. Incidence of and risk fac-tors for incisional hernia after abdominal surgery. Br J Surg 2014; 101: 1439-1447.
6. Goel TC, Dubey PC. Abdominal incisional hernia- Anatomical technique of repair. Indian J Surg. 1981; 43: 324-27.

7. Ponka JL, Hernias of the abdominal wall. Philadelphia, PA: WB Saunders; 1981.

8. Devlin HB, Kingsmith HB. Abdominal wall and hernias. Chapter 10th in A new aids companion in surgical studies, 2nd ed. Keim GB Lunard, Edingburgh Churchill Livingstone;1998:688-99.

9. Jack A. "Hernias" Chapter 14th In: Zinner MJ, Schwartz S, Ellis H, Editors. Maingot's Abdominal Operations. 10th ed. Connecticut: Prentice hall international Inc. 1997; 1: 479.

10. Junge K, Rosch R, Klinge U, Schwab R, Peiper C, Binnebosel $\mathrm{M}$, et al. Risk factors related to recurrence in inguinal hernia repair: a retrospective analysis. Hernia. 2006; 10: 309-15

11. Lau H, Fang C, Yuen WK, Patil NG. Risk factors for inguinal hernia in adult males: A case-control study. Surgery. 2007; 141: $262-6$

12. Rutkow IM. Demographic and socioeconomic aspects of hernia repair in the United States in 2003. Surg Clin North Am. 2003; 83: 1045.

13. Burger JW, Halm JA, Wijsmuller AR, ten Raa S, Jeekel J. Evaluation of new prosthetic meshes for ventral hernia repair. Surg Endosc. 2006; 20(8): 1320-5

14. The EU Hernia Trialists Collaboration. Repair of groin hernia with synthetic mesh: meta-analysis of RCT. Annals of Surgery 2002; 235: 322-32.

15. Luijendijk RW, Hop WC, van den Tol MP, et al. A comparison of suture repair with mesh repair for incisional hernia. N Engl J Med 2000;343(6):392-8.

16. Luijendijk RW. "Incisional hernia": risk factors, prevention, and repair. (Ph.D. thesis) Rotterdam, the Netherlands: Erasmus University Rotterdam, 2000

17. Gilbert AI, Felton LL. Infection in inguinal hernia repair considering biomaterials and antibiotics. Surg Gynecol Obstet. 1993; 177: 126.

18. Mudge M, Hughes LE. Incisional hernia: a 10-year prospective study of incidence and attitudes. Br J Surg 1985; 72: 70-1.

19. Jenkins TP. The burst abdominal wound: a mechanical approach. Br J Surg 1976; 63: 873-6.

20. Çobani, D.., Dogjani, A., Gjata, A. , Haxhirexha , K. ., Çeliku, E. ., Kolani , H. ., \& Kaçi, M. (2021). Incisional abdominal hernias, some consideration about it. International Journal of Medical Science and Clinical Invention, 8(10), 5683-5686. https://doi.org/10.18535/ijmsci/v8i10.02 